ENCYCLOPEDDIE Encyclopédie berbère

BERBERE

$10 \mid 1991$

10 | Beni Isguen - Bouzeis

\title{
Beni Snous
}

Voir Beni Iznasen

J. Despois, A. Raynal et S. Chaker

\section{CpenEdition}

Journals

Édition électronique

URL : http://journals.openedition.org/encyclopedieberbere/1688

DOI : $10.4000 /$ encyclopedieberbere.1688

ISSN : 2262-7197

Éditeur

Peeters Publishers

Édition imprimée

Date de publication : 1 décembre 1991

Pagination : 1468-1470

ISBN : 2-85744-549-0

ISSN : 1015-7344

Référence électronique

J. Despois, A. Raynal et S. Chaker, « Beni Snous », Encyclopédie berbère [En ligne], $10 \mid$ 1991, document B64, mis en ligne le 01 mars 2013, consulté le 24 septembre 2020. URL : http://

journals.openedition.org/encyclopedieberbere/1688; DOI : https://doi.org/10.4000/ encyclopedieberbere.1688

Ce document a été généré automatiquement le 24 septembre 2020.

(c) Tous droits réservés 


\title{
Beni Snous
}

\author{
Voir Beni Iznasen
}

J. Despois, A. Raynal et S. Chaker

\section{Extrait de Géographie de l'Afrique du Nord-Ouest (J. Despois et A. Raynal)}

1 Le groupe berbérophone des Beni Snous occupe la Ghaba occidentale, c'est-à-dire l'ensemble des plateaux calcaires de la Haute Tafna à l'ouest-sud-ouest de Tlemcen.

2 La Ghaba est un milieu rude : suffisamment arrosé dans son ensemble (600 à $700 \mathrm{~mm}$ ) mais froid, avec 10 à 20 chutes de neige par an, des gelées nombreuses, parfois de longues périodes sèches et du siroco. La forêt est plus utile comme pâturage que comme fournisseur de bois. Ses cours d'eau, permanents pour la plupart, et ses sources permettent le jardinage; mais les cultures sèches sont limitées par l'absence ou la médiocrité des sols. La Ghaba est au total, à l'exception de quelques vallées, plus favorable à l'élevage qu'aux cultures. Les vallées de la Ghaba sont parsemées de villages en ruines qui attestent l'extension d'une ancienne vie villageoise plus ou moins sédentaire telle qu'elle subsiste encore chez les Beni Snous.

3 Isolés dans les vallées de la Haute Tafna et du Khemis, les Beni Snous ont maintenu et conservé une économie et un genre de vie qui ont dû être celui d'une grande partie de la Ghaba avant le XII ${ }^{e}$ siècle, et ils parlent encore le berbère, du moins en famille. Renforcés par une immigration ancienne des gens du Figuig, ils sont demeurés des villageois et des arboriculteurs. Leurs champs s'étagent en terrasses irriguées, comme dans les pays pré-sahariens, portant de nombreux oliviers, des figuiers, des amandiers, des noyers et quelques pieds de vigne, et aussi des planches de luzerne, d'oignons, de tomates et de cucurbitacées. Plus que le blé qui donne de maigres résultats en culture sèche, les gens sèment du sorgho et surtout du maïs qu'ils irriguent.

4 L'élevage du petit bétail est encore une ressource complémentaire non négligeable. Une partie des familles des Beni Snous ont de petites tentes faites en poil de chèvre et en bourre de palmier nain avec lesquelles ils suivent leur troupeau dans leurs petits 
déplacements du printemps. Les femmes font des nattes d'alfa brodées de laine; les hommes travaillent un peu en forêt, entretiennent des ruches en écorce de liège, recueillent en octobre les glands des chênes verts qui seront écrasés et mêlés à la farine en cas de disette. Les villageois du Kef pêchent barbeaux et anguilles dans la Tafna.

5 Comme dans les montagnes pré-sahariennes les villages, tels le Kef ou le Khemis, agglomèrent leurs maisons de pierre sèche, au flanc des vallées, au-dessus des champs irrigués. Au Mazzer, situé à 1200 mètres, les terrasses des maisons sont percées de cheminées qui permettent le chauffage. Le bétail est abrité dans les cours des maisons, ou encore dans des grottes naturelles ou aménagées dans le calcaire.

\section{Beni Snous (linguistique) (S. Chaker)}

Petit îlot berbérophone de l'ouest algérien, situé entre Tlemcen et la frontière marocaine. Au plan linguistique, les B.S. peuvent être rattachés à l'ensemble rifain et plus particulièrement aux Beni Iznassen*, dont ils partagent la plupart des particularités. Alfred Willms, dans son essai de classification des dialectes berbères (1980 : 97), le situe dans le groupe 2 (Maroc-Nord et Algérie-Ouest) où il constitue avec le parler des Beni Iznassen et celui des Sanhaja de Sraïr le premier sous-groupe (distinct du Rif proprement dit).

7 Comme dans toute cette zone, la spirantisation des anciennes occlusives simples est très avancée et touche :

- les dentales : /t/, normalement réalisé [t] : tiššerț « ail », tazult « antimoine », tmart "barbe ». La spirante évolue parfois même jusqu'au souffle laryngal $[\mathrm{h}]$ : nihnin < ninnin « eux »;/d/ est normalement réalisé [d] : ayi1 «chien»; les palato-vélaires : / $\mathrm{k} /$ est régulièrement traité en $[\check{s}]:$ šal < (a)kal «terre ", ziš < zik «autrefois ", išerri < ikerri «bélier »; en position implosive ou inter-vocalique, /k/ et /g/ évoluent vers la semivoyelle: tyzzelt < tigzzelt «rein»; aysum «viande»; la tendance peut atteindre la vocalisation complète (sans doute avec longueur) : tissineft < tissgneft « aiguille », ayursel < agursel « champignon ».

On y relève également la chute fréquente de la voyelle initiale $a$ - des noms masculins singulier, surtout (mais pas uniquement) sur les thèmes mono-syllabiques: fus < afus « main », lum < alum « paille », țmart < tamart « barbe »...

9 Le parler berbère des B.S. a très tôt bénéficié d'une exploration approfondie grâce aux travaux de Destaing, dont plusieurs sont en outre d'un grand intérêt ethnographique (1905/a). Malheureusement, depuis ces publications anciennes, le parler ne semble avoir fait l'objet d'aucune étude. On ne dispose donc actuellement pas de données publiées récentes sur ses évolutions éventuelles et surtout sur sa vitalité.

\section{BIBLIOGRAPHIE}

DESTAING E., « L'Ennayer chez les Beni Snous », Revue Africaine, 1905, pp. 51-70 (texte). 
DESTAING E., «Le fils et la fille du roi », Recueil de mémoires et de textes publié en l'honneur du XIV Congrès International des Orientalistes, Alger, Fontana, 1905 a, pp. 179-195 (texte).

DESTAING E., «Quelques particularités sur le dialecte berbère des Beni Snous », Actes du XIV Congrès International des Orientalistes, Alger ( $4^{\mathrm{e}}$ section, 1905 b, pp. 93-99.

DESTAING E., « Fêtes et coutumes saisonnières chez les Beni Snous », Revue Africaine, 1907, pp.

24-284.

DESTAING E., Étude sur le dialecte des Beni Snous, Paris, Leroux, 1907-1911, 2 vol. 377 + 332 p.

DESTAING E., Dictionnaire français-berbère (dialecte des Beni Snous), Paris, Leroux, 1914.

KOSSMAN M., «L'inaccompli négatif en berbère ", Etudes et documents berbères, t. 6, 1989, pp. 19-29.

WILLMS A., Die dialektale Differenzierung des Berberischen, Berlin, Reimer, 1980.

INDEX

Mots-clés : Algérie, Art rupestre, Linguistique 